\title{
Effect of Alirocumab on Coronary Plaque in Patients With Coronary Artery Disease Assessed by Optical Coherence Tomography
}

\section{Fei Gao}

Beijing An Zhen Hospital: Capital Medical University Affiliated Anzhen Hospital

\section{Zhi Jian Wang}

Beijing An Zhen Hospital: Capital Medical University Affiliated Anzhen Hospital

\section{Xiao Teng Ma}

Beijing An Zhen Hospital: Capital Medical University Affiliated Anzhen Hospital

\section{Hua Shen}

Beijing An Zhen Hospital: Capital Medical University Affiliated Anzhen Hospital

\section{Li Xia Yang}

Beijing An Zhen Hospital: Capital Medical University Affiliated Anzhen Hospital

Yu Jie Zhou ( $\triangle$ azzyj12@163.com )

Beijing An Zhen Hospital: Capital Medical University Affiliated Anzhen Hospital

\section{Research Article}

Keywords: coronary artery disease, PCSK9 inhibitors, statins, coronary plaque, optical coherence tomography

Posted Date: July 9th, 2021

DOl: https://doi.org/10.21203/rs.3.rs-685343/v1

License: (c) (i) This work is licensed under a Creative Commons Attribution 4.0 International License. Read Full License 


\section{Effect of alirocumab on coronary plaque in patients with coronary artery disease} assessed by optical coherence tomography

Fei Gao, Zhi Jian Wang, Xiao Teng Ma, Hua Shen, Li Xia Yang, Yu Jie Zhou*.

Department of Cardiology, An Zhen Hospital, Capital Medical University, Beijing, China (1)

(1)

*Address for correspondence:

Yu Jie Zhou, M.D., Ph. D., F.A.C.C.

Department of Cardiology,

An Zhen Hospital, Capital Medical University,

Anzhenli avenue, Chao Yang district,

Beijing, 100029, China

Tel: 86-010-64456028

Fax: 86-010-64442234

E-mail: azzyj12@163.com 
Abstract

Background: Proprotein convertase subtilisin kexin type 9 (PCSK9) inhibitors have been demonstrated with significant greater reduction of LDL cholesterol levels and cardiovascular events, compared with standard statin therapy. However, the evidence on the impact of PCSK9 inhibitors on coronary plaque composition and morphology are limited. (

Methods: In this prospective, open-label, randomized study, eligible patients with intermediate coronary lesions and elevated LDL cholesterol values were randomized to either alirocumab $75 \mathrm{mg}$ Q2W plus statin therapy (alirocumab arm) or statin therapy (standard care arm). Optical coherence tomography (OCT) assessment for target lesions were obtained at the baseline and at 36 weeks of follow-up.

Results: LDL cholesterol levels were significantly decreased in both alirocumab arm and standard care arm, whereas the absolute reduction of LDL cholesterol was significantly greater in patients with alirocumab $(1.72 \pm 0.51$ vs $0.96 \pm 0.59, \mathrm{P}<0.0001)$. Compared with standard statin therapy, the addition of alirocumab to statins was associated with significant greater increase in minimum fibrous cap thickness (18.0 [10.8- 29.2]um vs 13.2 [7.4-18.6]um; $\mathrm{P}=0.029)$, minimum lumen area $\left(0.20[0.10-0.33] \mathrm{mm}^{2}\right.$ vs $\left.0.13[0.12-0.24] \mathrm{mm}^{2} ; \mathrm{P}=0.006\right)$ and greater diminution in maximum lipid $\operatorname{arc}\left(15.1^{\circ}[7.8-24.5]\right.$ vs. $\left.8.4^{\circ}[2.0-10.5] ; \mathrm{P}=0.008\right)$.

Conclusions: The addition of alirocumab to statins can not only provide additional LDL cholesterol lowering effect but also have a potential role in promoting a more stable plaque phenotype.

ClinicalTrials.gov Identifier: NCT04851769. Registered 2 Mar 2019, https://clinicaltrials.gov/ct2/show/NCT04851769

Keywords: coronary artery disease; PCSK9 inhibitors; statins; coronary plaque; optical coherence tomography 


\section{Introduction}

3

4 Low-density lipoprotein (LDL) cholesterol lowering therapy with statins is the cornerstone for

5 effective treatment of coronary artery disease [1, 2]. However, a substantial proportion of patients

6 cannot achieve target LDL cholesterol levels or tolerate effective doses despite treated with statin therapy [3, 4]. In fact, markedly increased residual cardiac risks were observed in this population [1]. Proprotein convertase subtilisin kexin type 9 (PCSK9) inhibitors in addition to statins have been demonstrated with significant greater reduction of LDL cholesterol levels as well as decreased incidence of adverse cardiovascular events, compared to statin therapy alone [5-7].

Recently, a series of intravascular ultrasound (IVUS) studies have demonstrated that adding PCSK9 inhibitors on top of statins achieved significantly greater percentage of atheroma volume regression [8-10]. Besides atheroma burden, fibrous-cap thickness is also an important indicator of plaque vulnerability $[11,12]$. However, due to the limited spatial resolution of IVUS, the influence of PCSK9 inhibition on fibrous-cap thickness cannot be assessed in these previous studies. Although the efficacy of LDL cholesterol lowering therapy on reducing coronary atheroma burden and increasing fibrous-cap thickness has been well established with statins [13,14], it remains unclear whether adding PCSK9 inhibitors to statins could further improve the thickness of fibrous-cap in coronary plaque. Optical coherence tomography (OCT) is currently the golden standard on evaluation of small changes in the fibrous-cap thickness [15,16]. Therefore, the aim of our study is to evaluate the impact of PCSK9 inhibitors plus statins on fibrous-cap thickness in patients with intermediate coronary lesions by OCT imaging.

\section{Methods}

The study is a prospective, open-label, single-center, randomized study involving patients with intermediate coronary lesions (50\%-70\% diameter stenosis) and who have elevated LDL cholesterol values despite stable statin therapy. From Mar 2019 to Jan 2020, all consecutive patients hospitalized 
1 China), which is a teaching hospital performing over 15000 percutaneous coronary intervention

2 procedures each year, were evaluated. Eligible patients included those who were (I) $18-80$ years

3 of age, (II) diagnosed as stable coronary artery disease or acute coronary syndrome on admission

4 (III) undergoing clinically indicated coronary angiography and identified with at least one

5 intermediate lesion (50\%-70\% diameter stenosis) on de novo coronary arteries, (IV) have an

6 elevated LDL cholesterol values (LDL cholesterol $\geq 1.81 \mathrm{mmol} / \mathrm{L}[\geq 70 \mathrm{mg} / \mathrm{dL}]$ for patients with acute coronary syndrome $[\mathrm{ACS}]$ or $\geq 2.59 \mathrm{mmol} / \mathrm{L}[\geq 100 \mathrm{mg} / \mathrm{dL}]$ for non-ACS patients) despite taken rosuvastatin $10 \mathrm{mg}$ /day or atorvastatin $20 \mathrm{mg} /$ day for $2-4$ weeks after initiation or with maximally tolerated statin therapy, (V) able to provide written, informed consent. Study exclusion criteria are listed in Table 1.

The study included a 36-week open-label treatment period (including post-treatment OCT imaging), starting within 4 weeks of baseline coronary angiogram (Figure. 1). During the open-label treatment period, patients were randomized 1:1 to either alirocumab arm or standard care arm. Patients in the alirocumab arm received alirocumab $75 \mathrm{mg}$ Q2W on top of statin therapy (atorvastatin $20 \mathrm{mg} /$ day or rosuvastatin $10 \mathrm{mg} /$ day). The last dose of alirocumab were given at week 34 . Patients in the standard care arm continued to receive atorvastatin $20 \mathrm{mg} /$ day or rosuvastatin $10 \mathrm{mg} /$ day. Statin dose escalation or adding other concomitant non-statin lipid-lowering therapy could be considered by their responsible physician to achieve target LDL cholesterol levels. Antithrombotic therapy and other concomitant medications were exclusively decided by the responsible physicians. Follow-up coronary angiograms and OCT imaging analyses of the same vessels were carried out at the end of treatment period (at week $36 \pm 2$ weeks, depending on patient availability) in both study arms. Regular medical examination and laboratory tests were conducted at weeks 4, 12 and 36. All enrolled patients were monitored and evaluated for safety and any other adverse events during the study period. The study was approved by the local medical ethics committee, and informed consent was obtained from each patient.

\section{Optical coherence tomography}

OCT images were obtained at the baseline and at week $36 \pm 2$ weeks follow-up. Optical frequency domain imaging systems (Ilumien or Optis Imaging System ${ }^{\mathrm{TM}}$, Abbott Vascular, USA) were used. 
1 The imaging catheter was advanced $10 \mathrm{~mm}$ distal to the target lesions. Contrast injection was 2 previously tested to ensure a complete wash-out of the vessel lumen. All imaging analysis was 3 performed by an independent investigator who was blinded to the study protocol. The baseline and 4 follow-up OCT images were reviewed to match the target lesions based on the distance from 5 landmarks (e.g. branching sites and calcifications). Calibration was applied before OCT image analysis. Values of minimal lumen area, minimal fibrous cap thickness, and maximal lipid arc were measured. The target plaque was characterized using previously validated criteria [17]. The minimum lumen area in each target lesion was calculated by an automated measurement algorithm and manual corrections. Minimum fibrous cap thickness was determined as the smallest fibrous cap thickness in the three candidate frames selected by manual screening. Maximum lipid arc was determined as the largest lipid arc from the center of the lumen in the three candidate frames selected by manual screening. The entire length of the target lesions and adjacent segments ( $5 \mathrm{~mm}$ proximal and distal) were evaluated at $1 \mathrm{~mm}$ intervals.

\section{Study endpoints}

The primary endpoint of the study was the OCT derived changes in minimum fibrous-cap thickness between the baseline and follow-up. Secondary endpoints included the changes in minimum lumen area between the baseline and follow-up, as well as the absolute changes in maximum lipid arc. In addition, the incidence of cardiac death, myocardial infarction (defined according to the fourth universal definition of myocardial infarction) [18], ischemia-driven target-lesion revascularization, major adverse cardiac events (defined as the composite outcome of death, myocardial infarction, and ischemia-driven target-lesion revascularization), and treatment related adverse reactions during the follow- up period were recorded as well.

\section{Statistical analysis}

Continuous variables are presented as mean \pm standard deviation or median (interquartile range), as appropriate. Categorical variables are reported as counts and percentages. Distribution was assessed for each variable with the Kolmogorov-Smirnov test. Comparison of continuous variables between the two groups were performed using the Mann-Whitney U test or the unpaired Student t test depending on their distributions. Continuous variables between the baseline and follow-up were 
compared by 1-sample Student $\mathrm{t}$ tests or the Wilcoxon signed rank test accordingly. Categorical variables were compared by chi-squared or Fisher's exact test. A two-tailed p-value $<0.05$ was regarded as statistically significant. The IBM SPSS Statistics 25.0 package was used.

\section{Results}

A total of 61 eligible patients ( 31 patients in the standard care arm and 30 patients in the alirocumab arm) with complete clinical and OCT imaging follow-up were analyzed. Nearly half of the patients $(15 / 31)$ in the standard care arm received ezetimibe and statin combination therapy. The clinical characteristics were listed in Table 2 . Of note, patients were predominantly male and had a high prevalence of cardiovascular risk factors. Both groups demonstrated a high rate of prescription of guidelines recommended medical therapies. All the participants were prescribed with antiplatelet therapy, and approximately $90 \%$ of them were treated with beta blockers. The baseline and procedural characteristics were not statistically significantly different between the two groups.

Biochemical measures throughout the study were summarized in Table 3. At baseline, no significant differences were observed between the standard care arm and the alirocumab arm. At 36 weeks, LDL cholesterol levels were significantly decreased in both groups compared with baseline, from $3.18 \mathrm{mmol} / \mathrm{L}$ to $2.22 \mathrm{mmol} / \mathrm{L}(\mathrm{P}<0.0001)$ in standard care arm, and from $3.04 \mathrm{mmol} / \mathrm{L}$ to 1.32 $\mathrm{mmol} / \mathrm{L}$ in alirocumab arm $(\mathrm{P}<0.0001)$, respectively. However, the absolute changes of $\mathrm{LDL}$ cholesterol levels were significantly higher in patients with alirocumab $(1.72 \pm 0.51$ vs $0.96 \pm 0.59$, $\mathrm{P}<0.0001)$. In addition, patients in alirocumab arm demonstrated favorable changes in triglycerides levels, but it did not attain statistical significance. C-reactive protein (CRP) levels decreased in both groups, but no significant difference was observed between the groups.

OCT-derived baseline parameters did not significantly differ between the two groups (Table 4). However, at 36 weeks follow-up, a significant greater increase in the changes of minimum fibrous cap thickness (18.0 [10.8- 29.2]um vs 13.2 [7.4-18.6]um; $\mathrm{P}=0.029)$ and the changes of minimum lumen area $\left(0.20[0.10-0.33] \mathrm{mm}^{2}\right.$ vs $\left.0.13[0.12-0.24] \mathrm{mm}^{2} ; \mathrm{P}=0.006\right)$ were observed in the alirocumab group compared to the standard care group. Similarly, the absolute changes of maximum 
1 lipid arc were also significantly greater in the alirocumab group compared to the standard care group $\left(15.1^{\circ}[7.8-24.5]\right.$ vs. $\left.8.4^{\circ}[2.0-10.5] ; \mathrm{P}=0.008\right)$. Additionally, patients in alirocumab arm demonstrated a numerically greater but not statistically significant reduction in the percentage of TACF compared to those in standard care arm (3.3\% vs $16.1 \%$; $\mathrm{P}=0.09)$.

No death or myocardial infarction event was found in either alirocumab or standard care arm (Table 5). However, there was 1 ischemia driven target lesion revascularization occurred in the standard care arm, but not in the alirocumab arm. Treatment-related adverse reactions were reported at generally similar frequencies in both groups. Nasopharyngitis (SoC: 1 patient; alirocumab: 2 patients) was the most common reaction. In total, 2 (6.7\%) patients in the alirocumab group experienced local injection-site reaction. All the treatment-related adverse reactions found in this study were classified as mild in intensity, and all the participants were tolerated to continue to receive study treatment.

\section{Discussion}

The results of our study indicated that the addition of alirocumab to statins was associated with significant greater reduction of LDL cholesterol levels, greater increase in fibrous cap thickness, and greater diminution in maximum lipid arc, compared with standard statin therapy.

The effect of lipid lowering therapy on the atheroma plaque morphology was initially established in statin trials [19]. Coronary plaque regression can be achieved when the decrease in LDL cholesterol level exceeded 50\% due to the treatment of statins [20]. However, our previous epidemiology study indicated large numbers of patients cannot achieve enough LDL cholesterol reductions despite treated with statin therapy [3]. PCSK9 inhibitors are novel pharmacologic agents, and it has been shown that the addition of a PCSK9 inhibitor to statins can further reduce LDL cholesterol levels by 43 to 64\% [21]. However, the evidence on the impact of PCSK9 inhibitors on atheroma plaque composition and morphology was limited. The ODYSSEY J-IVUS trials showed that the addition of alirocumab to statins resulted in a trend of greater reduction in total atheroma volume, but it did not attain statistical significance due to limited sample size and treatment duration 
1 [10]. The GLAGOV trial, on the other hand, reported a significant reduction on atheroma volume 2 by lowering LDL cholesterol to the level of $36 \mathrm{mg} / \mathrm{dL}$ with 76 weeks treatment of evolocumab plus statins [8]. However, the GLAGOV trial showed that the addition of evolocumab did not produce differential changes in plaque composition compared with statin monotherapy by IVUS assessment. While in these two studies the addition of PCSK9 inhibitors have been shown to reduce plaque burden, there is a gap of evidence regarding the impact of PCSK9 inhibition on changes of other presumed vulnerable plaque features, for instance, fibrous cap thickness. OCT imaging analysis, which provides a detailed image of ten times greater resolution than that achieved with IVUS, is the ideal imaging modality to assess the fibrous cap thickness of coronary plaque [16,22]. In a recent retrospective, observational OCT study revealed that compared to statin monotherapy, statin plus evolocumab provided a greater increase in fibrous-cap thickness of coronary plaques in patients with recent acute coronary syndrome [23]. The results of our study were consistent with the previous findings and we demonstrated a significant greater increase in minimum lumen area in the alirocumab arm assessed by OCT imaging. Notably, the addition of alirocumab to statins was associated with significant greater increase in fibrous cap thickness, and greater reduction in maximum lipid arc, compared with standard statin therapy. The current results indicated that the addition of alirocumab to statins can not only provide additional LDL cholesterol lowering effect but also have a potential role in promoting a more stable plaque phenotype.

Interestingly, our study observed no incremental reduction in CRP with treatment of alirocumab. These findings provide additional evidence suggesting that the effects of PCSK9 inhibition are exclusively due to favorable effects on lipids. Although statins have demonstrated with pleiotropic effects and CRP lowering associated with benefits on plaque regression $[24,25]$ and cardiovascular events risks [26], PCSK9 inhibitors have not yet been reported with a similar effect.

There are potential limitations to our study. The first major limitation of our study is the relatively small number of patients and the short treatment duration for follow-up OCT. Another important limitation is that there is no compelling evidence demonstrating a direct relationship between the increase of fibrous-cap thickness by OCT and the improvements on adverse cardiovascular events. However, there is a series of pathological research demonstrate that the thickness of the fibrous cap 
1 is a major determinant of plaque vulnerability $[11,27]$. Furthermore, it is well acknowledged that

2 OCT-based thin-cap fibroatheroma is associated with the presence of high-risk features evaluated

3 by other imaging modalities such as virtual histology intravascular ultrasound [28], all of which

4 have a strong link to future adverse clinical events [22,29]. Therefore, to date the thickening of the

5 fibrous cap has been considered as the representation of coronary plaque stabilization [30-33].

6 Further studies are needed to clarify the clinical implications of the changes in fibrous cap thickness

7 measured by OCT.

8

\section{Abbreviations}

10 LDL: Low-density lipoprotein; PCSK9: proprotein convertase subtilisin kexin type 9; IVUS:

11 intravascular ultrasound; OCT: optical coherence tomography; ACS: acute coronary syndrome;

12 CRP: C-reactive protein

\section{Declarations}

Ethics approval and consent to participate

17 The study protocol was approved by Ethics Committee of Beijing Anzhen Hospital, Capital university and all participants provided written informed consent. The study was performed in accordance with the principles of the Declaration of Helsinki.

Consent for publication

Not applicable.

Availability of data and materials

The datasets used and/or analysed during the current study are available from the corresponding author on reasonable request.

29 None. 
Funding

The study was funded by the Capital's Funds for Health Improvement and Research.

$$
\text { Authors' contributions }
$$

F Gao and Y J Zhou were in charge of the study design and management. H Shen were responsible for the data resources and integrity. Z J Wang and X T Ma conducted the OCT Imaging analysis. L $\mathrm{X}$ Yang helped with data management and statistical analysis. F Gao analyzed the data and drafted the manuscript. The authors read and approved the final manuscript.

\section{Acknowledgements}

We thank the entire study team for their participation and contributions.

\section{References}

1. Arnett DK, Blumenthal RS, Albert MA, Buroker AB, Goldberger ZD, Hahn EJ, et al. 2019 ACC/AHA guideline on the primary prevention of cardiovascular disease: a report of the American College of Cardiology/American Heart Association Task Force on Clinical Practice Guidelines. Circulation. 2019;140(11):e596-e646. https://doi.org/10.1161/CIR.0000000000000678

2. Michos ED, McEvoy JW, Blumenthal RS. Lipid management for the prevention of atherosclerotic cardiovascular disease. N Engl J Med. 2019;381(16):1557-1567. https://doi.org/10.1056/NEJMra1806939

3. Gao F, Zhou YJ, Hu DY, Zhao YX, Liu YY, Wang ZJ, et al. Contemporary Management and Attainment of Cholesterol Targets for Pa-tients with Dyslipidemia in China Results of a Chinese Society of Cardiology National Survey -- REALITY-CHINA SURVEY. PLoS One. 2013;9;8(4):e47681. https://doi.org/10.1371/journal.pone.0047681

4. Nicholls SJ, Nissen SE, Prati F, Windecker S, Kataoka Y, Puri R, et al. Assessing the impact of PCSK9 inhibition on coronary plaque phenotype with optical coherence tomography: rationale and design of the randomized, placebo-controlled HUYGENS study. Cardiovasc Diagn Ther. 2021;11(1):120-129. https://doi.org/10.21037/cdt-20-684

5. Robinson JG, Farnier M, Krempf M, Bergeron J, Luc G, Averna M, Stroes ES, et al. Efficacy and safety of alirocumab in reducing lipids and cardiovascular events. N Engl J Med. 2015;372:1489-99. https://doi.org/10.1056/NEJMoa1501031

6. Sabatine MS, Giugliano RP, Keech AC, Honarpour N, Wiviott SD, Murphy SA, et al. Evolocumab and clinical outcomes in patients with cardiovascular disease. N Engl J Med. 2017;376:1713-22. https://doi.org/10.1056/NEJMoa1615664

7. Schwartz GG, Steg PG, Szarek M, Bhatt DL, Bittner VA, Diaz R, et al. Alirocumab and Cardiovascular Outcomes after Acute Coronary Syndrome. N Engl J Med. 2018;379:2097-2107. 
https://doi.org/10.1056/NEJMoa1801174

8. Nicholls SJ, Puri R, Anderson T, Ballantyne CM, Cho L, Kastelein JJP, et al. Effect of Evolocumab on Coronary Plaque Composition. J Am Coll Cardiol. 2018;72:2012-21. https://doi.org/10.1016/j.jacc.2018.06.078

9. Nicholls SJ, Puri R, Anderson T, Ballantyne CM, Cho L, Kastelein JJ, et al. Effect of evolocumab on progression of coronary disease in statin-treated patients: the GLAGOV randomized clinical trial. JAMA. 2016;316:2373-84. https://doi.org/10.1001/jama.2016.16951

10. Ako J, Hibi K, Tsujita K, Hiro T, Morino Y, Kozuma K, et al. Effect of Alirocumab on coronary atheroma volume in Japanese patients with acute coronary syndrome - the ODYSSEY J-IVUS trial. Circ J. 2019;83:2025-33. https://doi.org/10.1253/circj.CJ-19-0412

11. Virmani R, Kolodgie FD, Burke AP, Farb A, Schwartz SM. Lessons from sudden coronary death: a comprehensive morphological classification scheme for atherosclerotic lesions. Arterioscler Thromb Vasc Biol. 2000;20:1262-75. https://doi.org/10.1161/01.atv.20.5.1262

12. Kolodgie FD, Burke AP, Farb A, Gold HK, Yuan J, Narula J, et al. The thin-cap fibroatheroma: a type of vulnerable plaque: the major precursor lesion to acute coronary syndromes. Curr Opin Cardiol. 2001;16:285-92. https://doi.org/10.1097/00001573-200109000-00006

13. Komukai K, Kubo T, Kitabata H, Matsuo Y, Ozaki Y, Takarada S, et al. Effect of atorvastatin therapy on fibrous cap thickness in coronary atherosclerotic plaque as assessed by optical coherence tomography: the EASY-FIT study. J Am Coll Cardiol. 2014;64:2207-17. https://doi.org/10.1016/j.jacc.2014.08.045

14. Kini A, Vengrenyuk Y, Shameer K, Maehara A, Purushothaman M, Yoshimura T, et al. Intracoronary Imaging, Cholesterol Efflux, and Transcriptomes After Intensive Statin Treatment: The YELLOW II Study. J Am Coll Cardiol. 2017;69(6):628-640. https://doi.org/10.1016/j.jacc.2016.10.029

15. Kim Y, Johnson TW, Akasaka T, Jeong MH. The role of optical coherence tomography in the setting of acute myocardial infarction. J Cardiol. 2018;72:186-92. https://doi.org/10.1016/j.jjcc.2018.03.004

16. Kume T, Akasaka T, Kawamoto T, Okura H, Watanabe N, Toyota E, et al. Measurement of the thickness of the fibrous cap by optical coherence tomography. Am Heart J. 2006;152:755. e1e4. https://doi.org/10.1016/j.ahj.2006.06.030

17. Tearney GJ, Regar E, Akasaka T, Adriaenssens T, Barlis P, Bezerra HG, et al. Consensus standards for acquisition, measurement, and reporting of intravas- cular optical coherence tomography studies: a report from the International Working Group for Intravascular Optical Coherence Tomography Standardiza- tion and Validation. J Am Coll Cardiol. 2012;59:105872. https://doi.org/10.1016/j.jacc.2011.09.079

18. Thygesen K, Alpert JS, Jaffe AS, Chaitman BR, Bax JJ, Morrow DA, et al. Executive Group on behalf of the Joint European Society of Cardiology (ESC)/American College of Cardiology (ACC)/American Heart Association (AHA)/World Heart Federation (WHF) Task Force for the Universal Definition of Myocardial Infarction. J Am Coll Cardiol. 2018;72(18):2231-2264. https://doi.org/10.1016/j.jacc.2018.08.1038

19. Nicholls SJ, Ballantyne CM, Barter PJ, Chapman MJ, Erbel RM, Libby P, et al. Effect of two intensive statin regimens on progression of coronary disease. N Engl J Med. 2011;365:2078-87. https://doi.org/10.1056/NEJMoa1110874

20. Nissen SE, Tuzcu EM, Schoenhagen P, Brown BG, Ganz P, Vogel RA, et al. Effect of intensive 
compared with moderate lipid-lowering therapy on progression of coronary atherosclerosis: a randomized controlled trial. JAMA. 2004;291:1071-80. https://doi.org/10.1001/jama.291.9.1071

21. Del Pinto R, Grassi D, Properzi G, Desideri G, Ferri C. Low density lipoprotein (LDL) cholesterol as a causal role for atherosclerotic disease: potential role of PCSK9 inhibitors. High Blood Press Cardiovasc Prev. 2019;26:199-207. https://doi.org/10.1007/s40292-019-00323-7

22. Johnson TW, Räber L, di Mario C, Bourantas C, Jia H, Mattesini A, Gonzalo N, et al. Clinical use of intracoronary imaging. Part 2: acute coronary syndromes, ambiguous coronary angiography findings, and guiding interventional decision-making: an expert consensus document of the European Association of Percutaneous Cardiovascular Interventions. Eur Heart J. 2019;40(31):2566-2584. https://doi.org/10.1093/eurheartj/ehz332

23. Yano H, Horinaka S, Ishimitsu T. Effect of evolocumab therapy on coronary fibrous cap thickness assessed by optical coherence tomography in patients with acute coronary syndrome. J Cardiol. 2020;75(3):289-295. https://doi.org/10.1016/j.jjcc.2019.08.002

24. Nissen SE, Tuzcu EM, Schoenhagen P, Crowe T, Sasiela WJ, Tsai J, et al. Statin therapy, LDL cholesterol, C-reactive protein, and coronary artery disease. N Engl J Med. 2005;352:29-38. https://doi.org/10.1056/NEJMoa042000

25. Puri R, Nissen SE, Libby P, Shao M, Ballantyne CM, Barter PJ, et al. C-reactive protein, but not low-density lipoprotein cholesterol levels, associate with coronary atheroma regression and cardiovascular events after maximally intensive statin therapy. Circulation. 2013;128:2395-403. https://doi.org/10.1161/CIRCULATIONAHA.113.004243

26. Ridker PM, Cannon CP, Morrow D, Rifai N, Rose LM, McCabe CH, et al. C-reactive protein levels and outcomes after statin therapy. N Engl J Med. 2005;352:20-8. https://doi.org/10.1056/NEJMoa042378

27. Buja LM, Willerson JT. Role of inflammation in coronary plaque disruption. Circulation. 1994; 89:503-5. https://doi.org/10.1161/01.cir.89.1.503

28. Sawada T, Shite J, Garcia-Garcia HM, Shinke T, Watanabe S, Otake H, et al. Feasibility of combined use of intravascular ultrasound radiofrequency data analysis and optical coherence tomography for detecting thin-cap fibroatheroma. Eur Heart J. 2008;29:1136-46. https://doi.org/10.1093/eurheartj/ehn132

29. Stone GW, Maehara A, Lansky AJ, de Bruyne B, Cristea E, Mintz GS, et al. A prospective natural-history study of coronary atherosclerosis. N Engl J Med. 2011;364:226-35. https://doi.org/10.1056/NEJMoa1002358

30. Nishiguchi T, Kubo T, Tanimoto T, Ino Y, Matsuo Y, Yamano T, et al. Effect of early pitavastatin therapy on coronary fibrous-cap thickness assessed by optical coherence tomography in patients with acute coronary syndrome: the ESCORT study. JACC Cardiovasc Imaging. 2018;11:829-38. https://doi.org/10.1016/j.jcmg.2017.07.011

31. Zanchin C, Koskinas KC, Ueki Y, Losdat S, Häner JD, Bär S, et al. Effects of the PCSK9 antibody alirocumab on coronary atherosclerosis in patients with acute myocardial infarction: a serial, multivessel, intravascular ultrasound, near-infrared spectroscopy and optical coherence tomography imaging study-Rationale and design of the PACMAN-AMI trial. Am Heart J. 2021;238:33-44. https://doi.org/10.1016/j.ahj.2021.04.006

32. Min JK, Chandrashekhar Y, Narula J. The immediate effects of statins on coronary atherosclerosis. JACC Cardiovasc Imaging. 2018;11:839-41. 
https://doi.org/10.1016/j.jcmg.2017.08.008

33. Otake H, Sugizaki Y, Toba T, Nagano Y, Tsukiyama Y, Yanaka KI, et al. Efficacy of alirocumab for reducing plaque vulnerability: Study protocol for ALTAIR, a randomized controlled trial in Japanese patients with coronary artery disease receiving rosuvastatin. J Cardiol. 2019;73(3):228-232. https://doi.org/10.1016/j.jjcc.2018.11.012

\section{Table legend}

Table 1. Exclusion criteria

Table 2. Baseline characteristics

Table 3. Biochemical parameters

Table 4. OCT -derived study endpoints

Table 5. Clinical events 
2 Table 1. Exclusion criteria

\section{Exclusion criteria}

Known hypersensitivity or contraindications to alirocumab and/or statin therapy

Received balloon angioplasty or stent implantation for target lesion

Unable to conduct OCT imaging analysis

Prior usage of PCSK9 inhibitors

Severe renal dysfunction ( creatinine clearance $<30 \mathrm{~mL} / \mathrm{min}$ )

Severe hepatic dysfunction

Baseline triglyceride $>400 \mathrm{mg} / \mathrm{dl}$

History of hemorrhagic stroke

Pregnant or breast-feeding women

Life expectancy $<1$ year

Inappropriate for the study for any reason based on the investigators' judgement 
Table 2. Baseline characteristics

2

\begin{tabular}{|l|l|l|l|}
\hline & $\begin{array}{l}\text { Standard of care } \\
(\mathbf{N}=\mathbf{3 1})\end{array}$ & $\begin{array}{l}\text { Alirocumab } \\
(\mathbf{N}=\mathbf{3 0})\end{array}$ & P Value \\
\hline Age, yrs & $61.3 \pm 9.9$ & $61.3 \pm 8.9$ & 0.97 \\
\hline Male & $74.2(23)$ & $66.7(20)$ & 0.52 \\
\hline Diabetes & $25.8(8)$ & $23.3(7)$ & 0.82 \\
\hline Current smoker & $25.8(8)$ & $30(9)$ & 0.72 \\
\hline Hypertension & $61.3(19)$ & $56.7(17)$ & 0.71 \\
\hline Prior MI & $9.7(3)$ & $13.3(4)$ & 0.65 \\
\hline Prior stroke & $3.2(1)$ & $10.0(3)$ & 0.28 \\
\hline ACS & $41.9(13)$ & $36.7(11)$ & 0.67 \\
\hline Antiplatelet & $100(31)$ & $100(30)$ & - \\
\hline Beta-blocker & $90.3(28)$ & $93.3(28)$ & 0.67 \\
\hline ACEI/ARB & $64.5(20)$ & $60.0(18)$ & 0.72 \\
\hline $\begin{array}{l}\text { Chronic statin before } \\
\text { enrollment }\end{array}$ & $32.3(10)$ & $26.7(8)$ & 0.63 \\
\hline Imaged artery & & & \\
\hline $\begin{array}{l}\text { Left anterior } \\
\text { desending }\end{array}$ & $41.9(13)$ & $43.3(13)$ & 0.91 \\
\hline Left circumflex & $22.6(7)$ & $26.7(8)$ & 0.71 \\
\hline Right coronary & $32.2(10)$ & $30.0(9)$ & 0.85 \\
\hline \begin{tabular}{l} 
Others \\
\hline
\end{tabular} & $3.2(1)$ & 0 & 0.32 \\
\hline
\end{tabular}

4

5 


\begin{tabular}{|c|c|c|c|}
\hline & $\begin{array}{l}\text { Standard of care } \\
(\mathrm{N}=\mathbf{3 1})\end{array}$ & $\begin{array}{l}\text { Alirocumab } \\
(\mathrm{N}=\mathbf{3 0})\end{array}$ & P Value \\
\hline \multicolumn{4}{|l|}{ LDL cholesterol, mg/dl } \\
\hline Baseline & $3.18 \pm 0.97$ & $3.04 \pm 0.78$ & 0.54 \\
\hline After 36 weeks treatment & $2.22 \pm 0.69$ & $1.32 \pm 0.39$ & $<0.0001$ \\
\hline Changes from baseline & $-0.96 \pm 0.59$ & $-1.72 \pm 0.51$ & $<0.0001$ \\
\hline \multicolumn{4}{|l|}{ HDL cholesterol, mg/dl } \\
\hline Baseline & $1.30 \pm 0.41$ & $1.41 \pm 0.61$ & 0.42 \\
\hline After 36 weeks treatment & $1.38 \pm 0.43$ & $1.48 \pm 0.47$ & 0.34 \\
\hline Changes from baseline & $0.08 \pm 0.36$ & $0.07 \pm 0.38$ & 0.86 \\
\hline \multicolumn{4}{|l|}{ Triglycerides, mg/dl } \\
\hline Baseline & $1.56(1.19$ to 2.38$)$ & 1.84 (1.19 to 2.56$)$ & 0.66 \\
\hline After 36 weeks treatment & 1.53 (1.09 to 2.26$)$ & 1.54 (1.00 to 2.09$)$ & 0.68 \\
\hline Changes from baseline & $-0.05(0.64$ to 1.42$)$ & $-0.29(-0.96$ to 0.35$)$ & 0.077 \\
\hline \multicolumn{4}{|l|}{$\mathrm{CRP}, \mathrm{mg} / \mathrm{l}$} \\
\hline Baseline & $1.62(0.90$ to 3.00$)$ & $1.69(0.75$ to 3.37$)$ & 0.80 \\
\hline After 36 weeks treatment & $1.10(0.89$ to 2.50$)$ & $1.59(0.92$ to 2.61$)$ & 0.64 \\
\hline Changes from baseline & $0.54(-0.46$ to 1.34$)$ & $0.12(-0.74$ to 1.08$)$ & 0.50 \\
\hline
\end{tabular}


1 Table 4. OCT -derived study endpoints

2

\begin{tabular}{|c|c|c|c|}
\hline & $\begin{array}{l}\text { Standard of care } \\
(\mathrm{N}=\mathbf{3 1})\end{array}$ & $\begin{array}{l}\text { Alirocumab } \\
(\mathbf{N}=\mathbf{3 0})\end{array}$ & P Value \\
\hline \multicolumn{4}{|l|}{$\begin{array}{l}\text { Minimum fibrous cap thickness, } \\
\text { um }\end{array}$} \\
\hline Baseline & $116.4(90.1$ to 136.2$)$ & $126.0(87.5$ to 145.5$)$ & 0.44 \\
\hline After 36 weeks treatment & $124.2(98.2$ to 144.3$)$ & $144.0(111.5$ to 151.8$)$ & 0.049 \\
\hline Changes from baseline & $13.2(7.4$ to 18.6$)$ & $18.0(10.8$ to 29.2$)$ & 0.029 \\
\hline \multicolumn{4}{|l|}{ Maximum lipid arc, degree } \\
\hline Baseline & $110.9(90.2$ to 132.4$)$ & $109.6(89.8$ to 130.0$)$ & 0.53 \\
\hline After 36 weeks treatment & $102.2(87.0$ to 123.1$)$ & $93.5(77.5$ to 108.1$)$ & 0.19 \\
\hline Changes from baseline & $-8.4(-2.0$ to -10.5$)$ & $-15.1(-7.8$ to -24.5$)$ & 0.008 \\
\hline \multicolumn{4}{|l|}{ Minimum lumen area, $\mathrm{mm}^{2}$} \\
\hline Baseline & $2.47(2.20$ to 2.74$)$ & $2.32(2.07$ to 2.63$)$ & 0.22 \\
\hline After 36 weeks treatment & $2.60(2.19$ to 2.90$)$ & $2.57(2.27$ to 2.90$)$ & 0.77 \\
\hline Changes from baseline & $0.13(0.12$ to 0.24$)$ & $0.20(0.10$ to 0.33$)$ & 0.006 \\
\hline \multicolumn{4}{|l|}{ TACF, $\%(n)$} \\
\hline Baseline & $25.8(8)$ & $20.0(6)$ & 0.59 \\
\hline After 36 weeks treatment & $16.1(5)$ & $3.3(1)$ & 0.09 \\
\hline
\end{tabular}

4 
Table 5. Clinical events

\begin{tabular}{|l|l|l|}
\hline $\begin{array}{l}\text { Standard of care } \\
(\mathrm{N}=\mathbf{3 1})\end{array}$ & $\begin{array}{l}\text { Alirocumab } \\
(\mathrm{N}=\mathbf{3 0})\end{array}$ \\
\hline
\end{tabular}

Adverse cardiac
events

\begin{tabular}{|l|l|l|}
\hline Cardiac death & 0 & 0 \\
\hline $\begin{array}{l}\text { Myocardial } \\
\text { infarction }\end{array}$ & 0 & 0 \\
\hline Ischemia driven & 1 & 0 \\
\hline
\end{tabular}

target lesion

revascularization,

Treatment-related

adverse events

\begin{tabular}{|l|l|l|}
\hline Nasopharyngitis & 1 & 2 \\
\hline $\begin{array}{l}\text { Injection-site } \\
\text { reaction }\end{array}$ & 0 & 2 \\
\hline $\begin{array}{l}\text { Back pain } \\
\begin{array}{l}\text { Transaminase } \\
\text { elevation }\end{array}\end{array}$ & 0 & 1 \\
\hline
\end{tabular}

2 


\section{Figures}

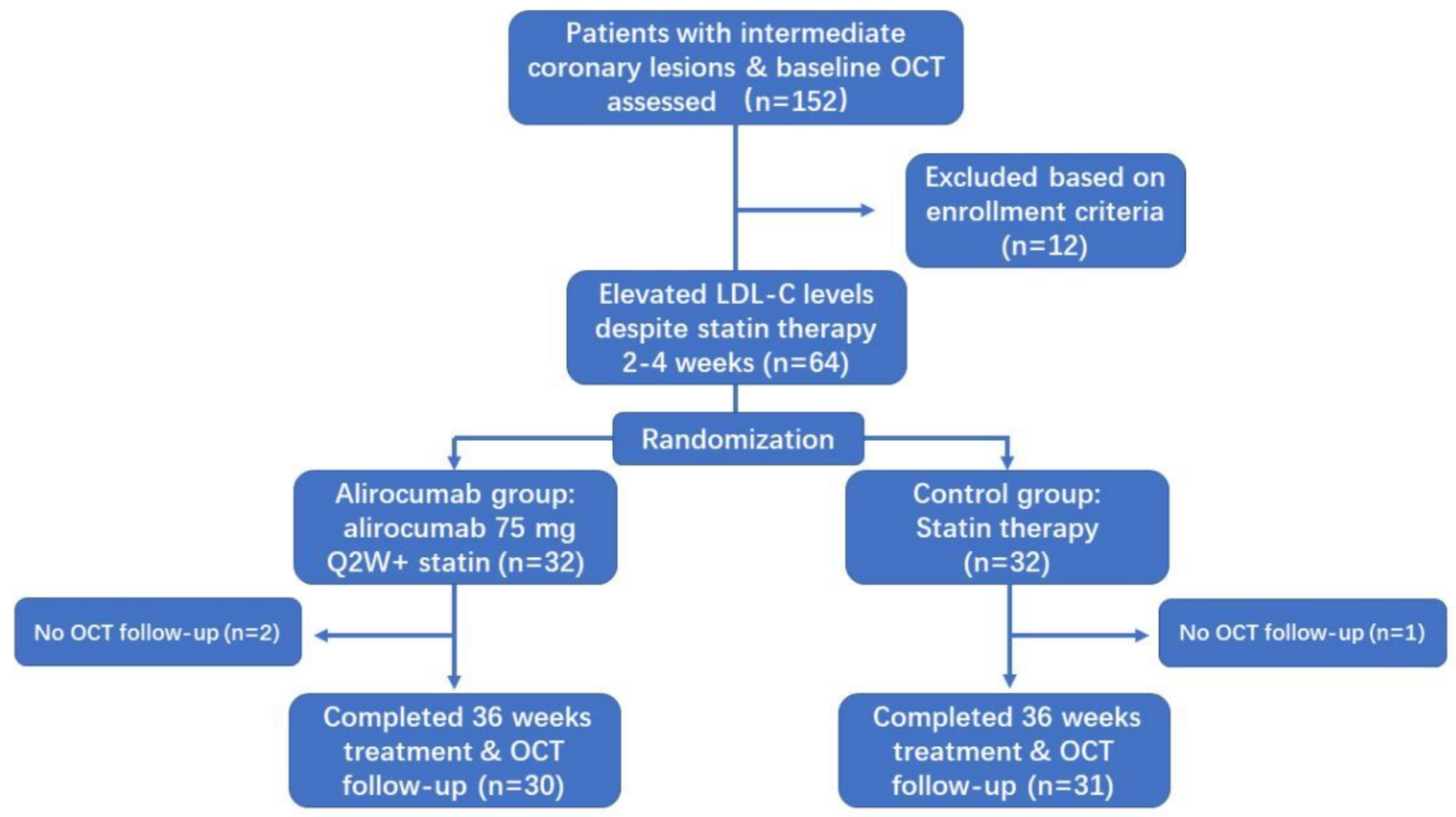

\section{Figure 1}

The study included a 36-week open-label treatment period (including post-treatment OCT imaging), starting within 4 weeks of baseline coronary angiogram (Figure. 1) 